Check for updates

Cite this: RSC Adv., 2017, 7, 28746

Received 8th April 2017

Accepted 24th May 2017

DOI: $10.1039 / \mathrm{c} 7 \mathrm{ra03990e}$

rsc.li/rsc-advances

\section{Pyrolysis of $n$-butane investigated using synchrotron threshold photoelectron photoion coincidence spectroscopy}

\author{
Xiaofeng Tang, (D) *a Xiaoxiao Lin, ${ }^{a}$ Yupeng Zhu, ${ }^{\text {ab }}$ Xiangkun Wu, ${ }^{\text {bc }}$ Zuoying Wen, ${ }^{\text {ab }}$ \\ Lidong Zhang, ${ }^{d}$ Fuyi Liu, ${ }^{d}$ Xuejun $\mathrm{Gu}^{\mathrm{a}}$ and Weijun Zhang*ae
}

\begin{abstract}
We present here the coupling of a flash pyrolysis micro-reactor with threshold photoelectron photoion coincidence (TPEPICO) spectroscopy at Hefei synchrotron to investigate thermal decomposition of $n$ butane. Primary products in the pyrolysis were determined with TPEPICO time-of-flight mass spectra and mass-selected threshold photoelectron spectra (TPES). Vibrational structures in the TPES of the $\mathrm{CH}_{3}$, $\mathrm{C}_{2} \mathrm{H}_{5}$ and $\mathrm{C}_{3} \mathrm{H}_{6}$ products were observed and their ionization energies were measured and compared satisfactorily to literature data. Moreover, the potential energy surface involved in the decomposition was calculated by using high-level quantum chemistry and several transition states were recognized. Then the detailed mechanisms of the pyrolysis of $n$-butane have been discussed and revealed.
\end{abstract}

\section{Introduction}

Thermal decomposition of hydrocarbons at high temperature plays an essential role in combustion and strongly links to atmospheric reactions to produce polycyclic aromatic hydrocarbons, soot and other toxic compounds. ${ }^{1-3}$ In the past, shock tubes, Knudsen cells and other pyrolysis reactors combing with a great number of analytical methods such as photo-absorption spectroscopy, ${ }^{4,5}$ gas chromatography $(\mathrm{GC})^{\mathbf{6}, 7}$ and photoionization mass spectrometry (PIMS $)^{3,8}$ have been adopted to elucidate the underlying chemistry. Typically, spectroscopic methods are usually used to probe products that only contain a few atoms, whereas unstable reactive species such as free radicals can be hardly observed by GC. PIMS as a universal method especially coupled with tunable vacuum ultraviolet (VUV) synchrotron radiation has been successfully utilized to identify various reaction products. Photoionization efficiency (PIE) spectra were adopted to discriminate isomers based on their different ionization energies. ${ }^{2,3}$ Photoelectron photoion coincidence spectroscopy (PEPICO) analyzes both electrons and ions simultaneously and offers the potential to provide additional

${ }^{a}$ Laboratory of Atmospheric Physico-Chemistry, Anhui Institute of Optics and Fine Mechanics, Chinese Academy of Sciences, Hefei, 230031 Anhui, China. E-mail: tangxf@aiofm.ac.cn; wjzhang@aiofm.ac.cn

${ }^{b}$ Graduate School, University of Science and Technology of China, Hefei, 230026 Anhui, China

${ }^{c}$ Hefei National Laboratory for Physical Sciences at the Microscale, Department of Chemical Physics, University of Science and Technology of China, Hefei 230026, China ${ }^{d}$ National Synchrotron Radiation Laboratory, University of Science and Technology of China, Hefei 230029, China

${ }^{e}$ School of Environmental Science and Optoelectronic Technology, University of Science and Technology of China, Hefei, 230026 Anhui, China and complementary information encoded in the electrons in the photoionization. ${ }^{9-12}$ In particular, the mass-selected threshold photoelectron spectrum (TPES) for each species can be obtained with PEPICO by scanning photon energy and collecting electrons with near zero kinetic energy and offer more detailed spectral information than PIE. In recent years PEPICO as an efficient analytical approach has started to be applied in complex systems such as combustion and atmosphere chemistry to identify products and isomers. ${ }^{13-15}$

The objective of the present study, $n$-butane is the prototype of hydrocarbons and an essential model fuel to study combustion behaviors. The thermal decomposition reactions of $n$ butane are important initiation steps in the high-temperature oxidation and strongly influence on the ignition time, ${ }^{\mathbf{1 6}}$ which have attracted a lot of attention in the past decades. A series of products from both the primary and the secondary pyrolysis reactions of $n$-butane have been identified and analyzed by using the methods of GC, Raman spectroscopy, electron impact ionization mass spectrometry and PIMS..$^{6,7,17-20}$ For example, for the major stable products of $\mathrm{CH}_{4}, \mathrm{C}_{2} \mathrm{H}_{4}, \mathrm{C}_{2} \mathrm{H}_{6}$ and $\mathrm{C}_{3} \mathrm{H}_{6}$, it was believed that the thermal decomposition reactions responsible for the production were mostly proceeded through free-radical chain reactions. ${ }^{6}$ But, these stable products may also be formed from the direct decomposition of $n$-butane and in recent quantum chemical calculations several transition states were determined on the potential energy surfaces of the dissociation of $n$-butane and can correlate to the production of the stable products. ${ }^{21}$

Recently, we have developed a molecular beam flash pyrolysis micro-reactor ${ }^{22-24}$ in combination with a threshold PEPICO (TPEPICO) spectrometer ${ }^{10}$ at Hefei synchrotron to explore VUV spectroscopy of organic radicals ${ }^{25}$ and thermal decomposition 
of hydrocarbons. Benefited from its high temperature and short contact time, the flash pyrolysis micro-reactor allows for the thermal decomposition with high efficiency and minimizes secondary reactions. ${ }^{26-28}$ The TPEPICO scheme provides a strategy to obtain pure spectra of products without contamination from other byproducts. As a representative example, thermal decomposition of $n$-butane has been selected and investigated by using the flash pyrolysis micro-reactor and the TPEPICO spectrometer. The primary pyrolysis products were identified and determined from TPEPICO time-of-flight (TOF) mass spectra and mass-selected TPES. In addition, the potential energy surface involved in the decomposition was also calculated by using high-level quantum chemistry and several transition states were recognized. With the results of experiments and theoretical calculations, a clear picture of the dissociation mechanisms has been revealed.

\section{Experimental setup}

The experiments were carried out on the Atomic and Molecular Physics beamline at National Synchrotron Radiation Laboratory (NSRL) in Hefei, China. Fig. 1 gives a schematic diagram of the whole setups including the VUV synchrotron beamline, the TPEPICO spectrometer and the molecular beam flash pyrolysis micro-reactor. The setups have already been introduced in detail in our previous papers and so only a brief description will be presented here. ${ }^{10,25}$

Synchrotron photons emitted from an undulator of $800 \mathrm{MeV}$ electron ring at NSRL were dispersed by a $6 \mathrm{~m}$ monochromator equipped with three gratings $(370,740$ and 1250 grooves per $\mathrm{mm}$ ) covering the photon energy range of 7.5-124 eV. To maximize photon flux, presently the slits of the monochromator were expanded with widths of $200 \mu \mathrm{m}$ and the photon energy resolution is about $20 \mathrm{meV}$ (full width at half maximum,

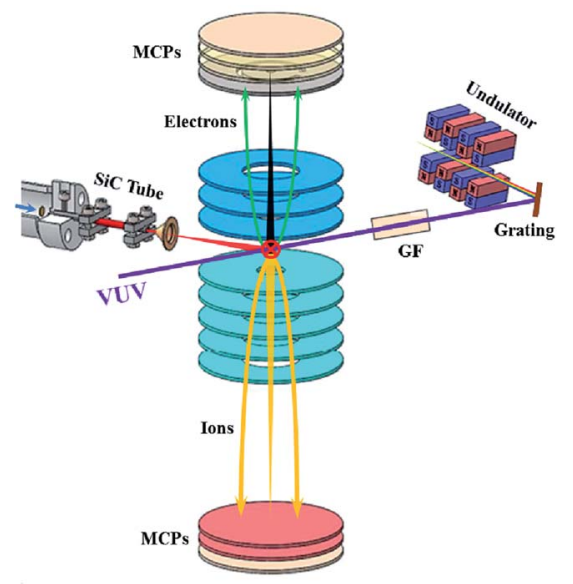

Fig. 1 Schematic diagram of the experimental setups including the VUV synchrotron beamline, the threshold photoelectron photoion coincidence (TPEPICO) spectrometer and the flash pyrolysis microreactor, where the photoionization region marked with a red crossing circle. Both electrons and ions were velocity focused and the trajectories of threshold electrons, hot electrons and ions are shown as black, green and yellow lines, respectively.
FWHM) at $h \nu=10 \mathrm{eV}$ with the 370 grooves per mm grating. A gas filter filled with argon was installed to suppress the highorder harmonic photons emitted from the undulator. The absolute photon energy of the monochromator was calibrated on-line with the absorption resonant lines of Ar in the gas filter. The photons were softly focused onto a spot with $\sim 1 \mathrm{~mm}(V) \times 2$ $\mathrm{mm}(H)$ size in the photoionization region. A photodiode just located behind the photoionization region was used to measure the photon flux for normalizing signals in the photon energy scans.

The TPEPICO spectrometer ${ }^{10}$ is mainly composed of two TOF analyzers with double velocity map imaging ${ }^{29}$ designs for ions and electrons respectively operated in coincidence. A mask with a small central hole and a concentric ring was installed and located at the front of electron micro-channel plates (MCPs) with a chevron configuration. The small central hole and the concentric ring were used to collect near zero kinetic energy photoelectrons (threshold photoelectrons) and hot electrons, respectively, which were velocity focused as shown by the black and green trajectories in Fig. $1 .^{30}$ After amplified, the electron signals were transferred to the start connector of a multipleevent time digitizers (P7888-2, FAST Comtec, Germany) and the ion signals to the stop connector. Then the electron signals provide start to record ion events in coincidence. The contribution of hot electrons that happen to the center of the electron detector was corrected by using the method of subtraction. ${ }^{30}$ TPES, especially mass-selected TPES corresponding to each species can be acquired in the coincidence mode by scanning synchrotron photon energy.

The flash pyrolysis micro-reactor ${ }^{25}$ is similar to the design of Chen et al. ${ }^{26}$ and primarily consists an orifice nozzle $(50 \mu \mathrm{m}$ diameter), a ceramic insulation plate and a silicon carbide tube (SiC, $1 \mathrm{~mm}$ inner diameter). The jet of $n$-butane seeded in argon with a stagnation pressure of 2 atm in the nozzle was adiabatically expanded into the SiC tube in vacuum and a continuous molecular beam with a subsonic speed was formed. The SiC tube was electrically connected to a DC power supply via a vacuum feedthrough port and the pyrolysis power can be controlled outside. The temperature inside the SiC tube was measured off-line with a thermocouple and can be approached at $\sim 1600 \mathrm{~K}$. The high temperature and the short contact time ( $\sim$ several tens of microseconds) due to the short heating length of the SiC tube $(\sim 15 \mathrm{~mm})$ and the fast speed of molecular beam allow for the thermal decomposition with high efficiency. Moreover, the flash pyrolysis micro-reactor was mounted on a manually-controlled XYZ manipulator in the source chamber of the TPEPICO spectrometer and its position can be tuned realtime to optimize the signals. The source and ionization chambers of the TPEPICO spectrometer were separated by a skimmer ( $1 \mathrm{~mm}$ diameter) and their backing pressures were $4 \times 10^{-2} \mathrm{~Pa}$ and $5 \times 10^{-5}$ Pa respectively with the molecular beam on.

\section{Results and discussion}

\subsection{TPEPICO time-of-flight mass spectra}

TPEPICO TOF mass spectrum, showing ions detected in coincidence with threshold electrons, of $n$-butane with no pyrolysis 
was measured at fixed photon energy of $h \nu=10.60 \mathrm{eV}$, just above the ionization energy of $n$-butane $(\mathrm{IE}=10.53 \pm 0.02 \mathrm{eV}){ }^{31}$ and is presented in Fig. 2(a). One peak at $m / z=58$ is observed with a narrow width and ascribed to $\mathrm{C}_{4} \mathrm{H}_{10}{ }^{+}$parent ion in the mass spectrum. When the pyrolysis power was turned on, as shown in Fig. 2(b) and (c) observed at $h \nu=10.60 \mathrm{eV}$ with the powers of $P=29 \mathrm{~W}$ and $36 \mathrm{~W}$, corresponding to the temperatures of $\sim 1200 \mathrm{~K}$ and $\sim 1400 \mathrm{~K}$ in the SiC tube, the intensities of the $\mathrm{C}_{4} \mathrm{H}_{10}{ }^{+}$peak in the mass spectra declined and dropped steadily with the power, meaning that $n$-butane precursor molecules had been thermally decomposed. At the same time, several other peaks at $m / z=15,28,29,42$ and 43 can be identified in the mass spectra and have been assigned as $\mathrm{CH}_{3}{ }^{+}$, $\mathrm{C}_{2} \mathrm{H}_{4}{ }^{+}, \mathrm{C}_{2} \mathrm{H}_{5}{ }^{+}, \mathrm{C}_{3} \mathrm{H}_{6}{ }^{+}$and $\mathrm{C}_{3} \mathrm{H}_{7}{ }^{+}$, whose ionization energies cited from references have been listed in Table 1.

In the mass spectra the widths of the $\mathrm{CH}_{3}{ }^{+}, \mathrm{C}_{2} \mathrm{H}_{4}{ }^{+}, \mathrm{C}_{2} \mathrm{H}_{5}{ }^{+}$, and $\mathrm{C}_{3} \mathrm{H}_{6}{ }^{+}$peaks are very narrow, similar to the peak of $\mathrm{C}_{4} \mathrm{H}_{10}{ }^{+}$ parent ion, indicating that they were also from photoionization of their neutral molecules. Their intensities increase with pyrolysis power. The peaks of $\mathrm{C}_{3} \mathrm{H}_{7}{ }^{+}$are much wider than those of the other ions and the $\mathrm{C}_{3} \mathrm{H}_{7}{ }^{+}$ions may be produced from different processes. Photoionization and dissociative photoionization of $n$-butane have been studied well previously by the method of photoionization mass spectrometry and $\mathrm{C}_{3} \mathrm{H}_{7}{ }^{+}$is the major fragment ion with the largest intensity in the dissociation. ${ }^{32}$ The appearance energy of $\mathrm{C}_{3} \mathrm{H}_{7}{ }^{+}$in dissociative photoionization of $n$-butane was measured at $11.18 \mathrm{eV}$ (ref. 32) which is above the present photon energy of $h \nu=10.60 \mathrm{eV}$. But, in the present experimental condition to arrive the photoionization region $n$-butane needed to go past the high-temperature SiC tube and the increased temperature can shift the onset of the dissociative photoionization. This effect of hot band has also

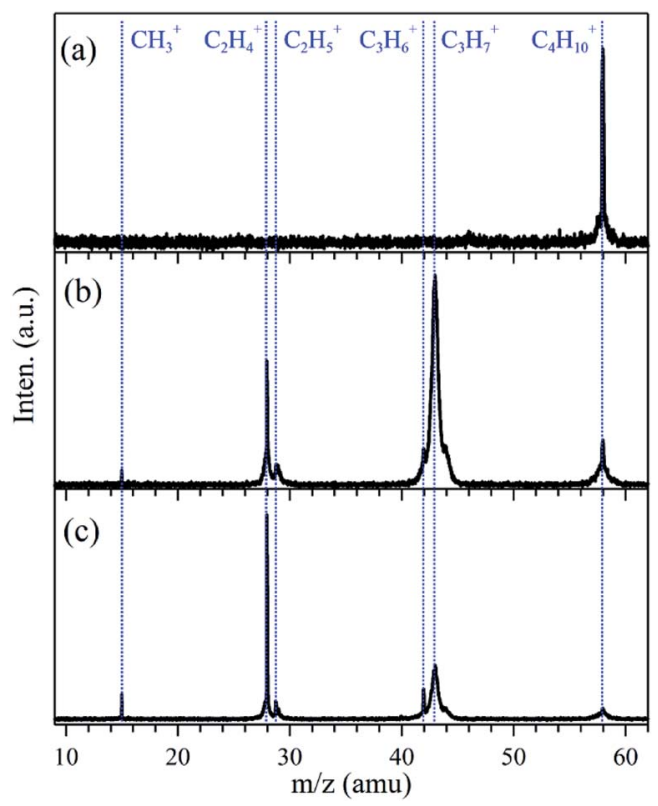

Fig. 2 TPEPICO TOF mass spectra recorded at fixed photon energy of $h \nu=10.60 \mathrm{eV}$ with (a) no pyrolysis, (b) pyrolysis power $P=29 \mathrm{~W}$, and (c) pyrolysis power $P=36 \mathrm{~W}$.
Table 1 lonization energies (IEs) of relevant species involved in the pyrolysis of $n$-butane ${ }^{a}$

\begin{tabular}{llcll}
\hline$m / z$ & Species & IE $(\mathrm{eV})$ & Methods & Ref. \\
\hline 58 & $n-\mathrm{C}_{4} \mathrm{H}_{10}$ & $10.53 \pm 0.02$ & Thermochemistry & 31 \\
57 & $1-\mathrm{C}_{4} \mathrm{H}_{9}$ & $8.02 \pm 0.04$ & PES & 31 \\
43 & $1-\mathrm{C}_{3} \mathrm{H}_{7}$ & $8.09 \pm 0.01$ & PES & 33 \\
42 & $\mathrm{C}_{3} \mathrm{H}_{6}$ & $9.7452 \pm 0.0005$ & PFI-ZEKE & 34 \\
30 & $\mathrm{C}_{2} \mathrm{H}_{6}$ & $11.5 \pm 0.1$ & TPES & 35 \\
29 & $\mathrm{C}_{2} \mathrm{H}_{5}$ & $8.117 \pm 0.008$ & PIMS & 36 \\
28 & $\mathrm{C}_{2} \mathrm{H}_{4}$ & $10.51 \pm 0.02$ & PES & 37 \\
16 & $\mathrm{CH}_{4}$ & $12.618 \pm 0.004$ & PFI-ZEKE & 38 \\
15 & $\mathrm{CH}_{3}$ & $9.8387 \pm 0.0018$ & PFI-ZEKE & 39
\end{tabular}

${ }^{a}$ PES: photoelectron spectroscopy; PFI-ZEKE: pulsed-field-ionization zero-kinetic-energy photoelectron spectroscopy.

been observed in the TPES of $\mathrm{CH}_{3}$, as shown in Fig. 4(a). Some kinetic energies should have been released in the dissociative photoionization and contribute to the wide width of the $\mathrm{C}_{3} \mathrm{H}_{7}{ }^{+}$ peak in the mass spectra.

The pyrolysis of $n$-butane may also produce the neutral $\mathrm{C}_{3} \mathrm{H}_{7}$ radical through the direct fission of the $\mathrm{C} 1-\mathrm{C} 2$ bond of $n$-butane in the SiC tube and the above observed $\mathrm{CH}_{3}$ can be its accompanied product. The signal of the $\mathrm{C}_{3} \mathrm{H}_{7}$ product is very weak, as demonstrated by the weak $\mathrm{CH}_{3}{ }^{+}$signal in the mass spectra of Fig. 2, and may be buried in the $\mathrm{C}_{3} \mathrm{H}_{7}{ }^{+}$wide peak. So we tried to change synchrotron photon energy and look for the evidence of the $\mathrm{C}_{3} \mathrm{H}_{7}$ product in TPEPICO TOF mass spectra. For example, with the fixed pyrolysis power of $P=36 \mathrm{~W}$, TPEPICO TOF mass spectra were measured at fixed photon energies of $h \nu=9.50$, 9.90 and $10.20 \mathrm{eV}$, all of which are far below the appearance energy of $\mathrm{C}_{3} \mathrm{H}_{7}{ }^{+}$in dissociative photoionization of $n$-butane, and are displayed in Fig. 3. Except the absence of the $\mathrm{C}_{4} \mathrm{H}_{10}{ }^{+}$parent

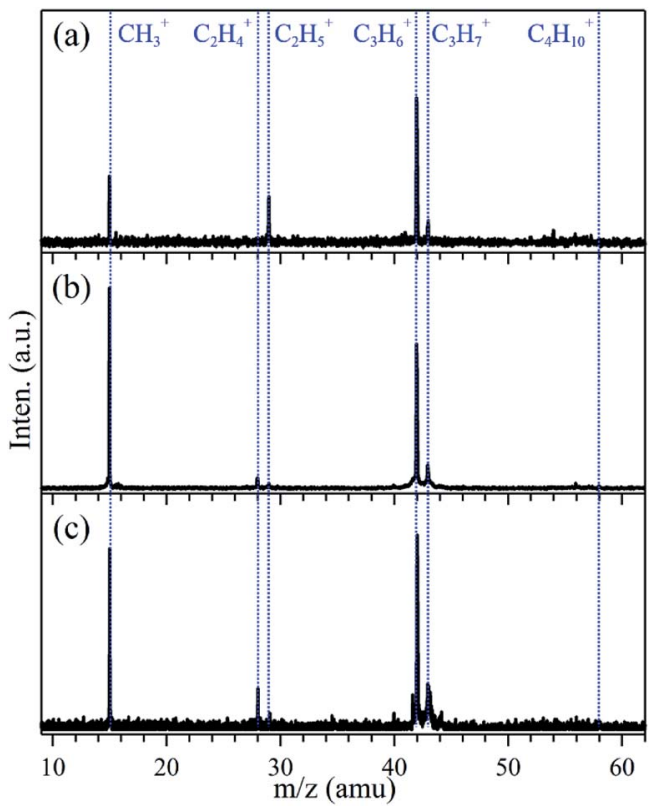

Fig. 3 TPEPICO TOF mass spectra recorded at different photon energies with pyrolysis power of $P=36 \mathrm{~W}$. (a) $h \nu=9.50 \mathrm{eV}$, (b) $h \nu=$ $9.90 \mathrm{eV}$ and (c) $h \nu=10.20 \mathrm{eV}$. 
ion, the peaks of $\mathrm{CH}_{3}{ }^{+}, \mathrm{C}_{2} \mathrm{H}_{4}{ }^{+}, \mathrm{C}_{2} \mathrm{H}_{5}{ }^{+}, \mathrm{C}_{3} \mathrm{H}_{6}{ }^{+}$and $\mathrm{C}_{3} \mathrm{H}_{7}{ }^{+}$ions can be determined in Fig. 3. All of them are very narrow in the mass spectra. Especially, in contrary to the case of Fig. 2, presently the peaks of $\mathrm{C}_{3} \mathrm{H}_{7}{ }^{+}$in the mass spectra do not take a wide width again indicating that they were only from photoionization of the propyl radicals.

\subsection{Mass-selected TPES}

The mass-selected TPES can be measured by scanning photon energy and provide detailed spectral fingerprint for each species. Especially rather than the steps in the PIE spectra, electronic states even fine vibrational structures of ions can appear as distinct peaks in the mass-selected TPES and offer great selectivity and sensitivity., ${ }^{3,13-15}$ As a representative, the mass-selected TPES of the methyl radical, ethyl radical and propylene products from pyrolysis of $n$-butane were recorded with a $15 \mathrm{meV}$ scanning step size in the energy range of 8.0$10.0 \mathrm{eV}$ and are depicted in Fig. 4. For the methyl radical, several peaks can be observed in the TPES and ascribed to the vibrational excitations in the photoionization. The adiabatic ionization energy of the methyl radical is measured at $h \nu=9.84 \mathrm{eV}$, which agrees well with the existing literature data,,$^{22,25,39,40}$ and is contributed to the most intense peak in Fig. 4(a). Taken into
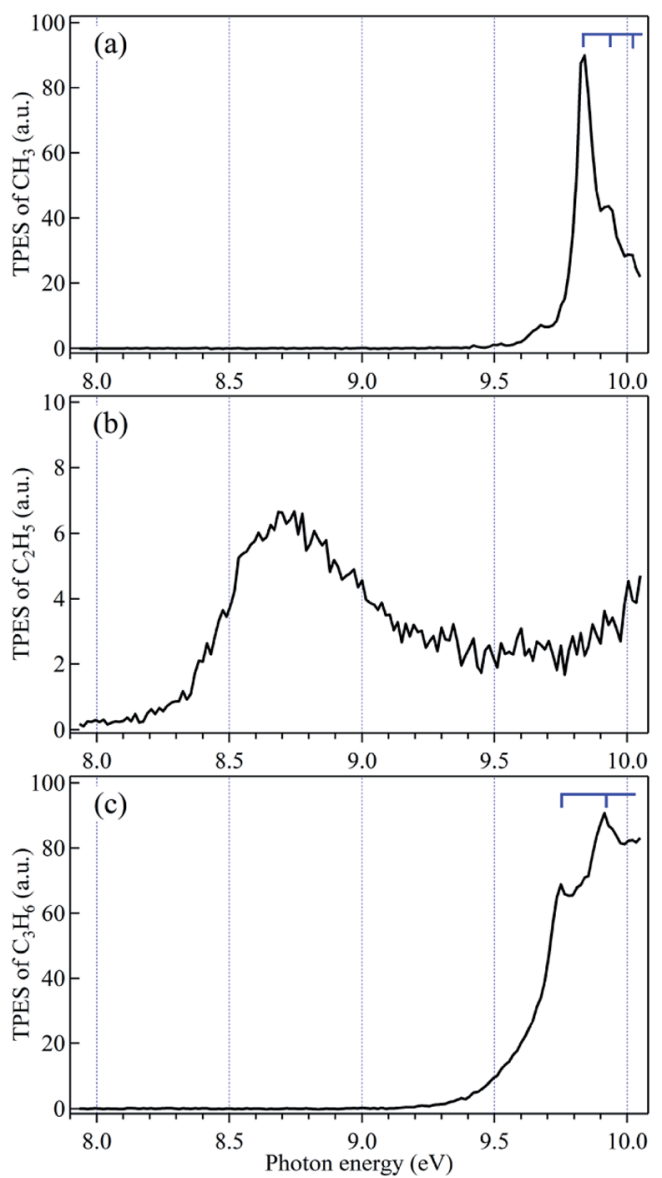

Fig. 4 Mass-selected threshold photoelectron spectra (TPES) of (a) $\mathrm{CH}_{3}$, (b) $\mathrm{C}_{2} \mathrm{H}_{5}$ and (c) $\mathrm{C}_{3} \mathrm{H}_{6}$ products from pyrolysis of $n$-butane. account the different symmetries of the neutral methyl radical $\left(C_{3 \mathrm{~V}}\right)$ and its corresponding ion $\left(D_{3 \mathrm{~h}}\right)$, the umbrella vibrational mode of $\mathrm{CH}_{3}{ }^{+}$had been excited in the photoionization and contributes to the other peaks. Some other peaks with very weak intensities below the adiabatic ionization energy can also be observed in the TPES and are from the contributions of hot band due to the high temperature in the pyrolysis. ${ }^{22,25}$

The TPES of ethyl radical is exhibited with a broad band in Fig. 4(b). The electron signal appears at $\sim 8.2 \mathrm{eV}$ and its intensity approaches the maximal at $h \nu=8.7 \mathrm{eV}$, contributing to the adiabatic and vertical ionization energies of ethyl radical, respectively. For propene product, as shown in Fig. 4(c), two vivid vibrational peaks can be observed in the TPES. The adiabatic ionization energy of propene is measured at $9.75 \mathrm{eV}$ and corresponds to the first peak. The other peak with a spacing of $165 \mathrm{meV}\left(1330 \mathrm{~cm}^{-1}\right)$ to the first peak is ascribed to the $\mathrm{C}=\mathrm{C}$ stretching vibrational population of $\mathrm{C}_{3} \mathrm{H}_{6}{ }^{+}{ }^{34,41}$ We had also tried to measure the TPES of the propyl radical from pyrolysis of $n$-butane. But, as we discussed in the above part of 3.1, the signals of $\mathrm{C}_{3} \mathrm{H}_{7}^{+}$were from two processes, photoionization of the propyl radical and dissociative photoionization of $n$-butane, and presently it is very difficult for us to discriminate them due to the restriction of the detectors. This problem can be overcome by employing position sensitive detectors (PSDs) to collect electrons and ions in coincidences and then the pure TPES of the propyl radical could be acquired with an ion-kinetic-energyfiltered method. ${ }^{42,43}$

\subsection{Pyrolysis mechanisms}

In previous studies, the stable products such as $\mathrm{CH}_{4}, \mathrm{C}_{2} \mathrm{H}_{4}$, $\mathrm{C}_{2} \mathrm{H}_{6}$ and $\mathrm{C}_{3} \mathrm{H}_{6}$ from pyrolysis of $n$-butane had been observed by the methods of GC, GC-mass spectrometer (GC-MS), Raman spectroscopy and synchrotron VUV PIMS..$^{6,16-20,44}$ It was suggested that these stable products were most likely to be produced through the following free-radical chain reactions: ${ }^{6}$

$$
\begin{gathered}
\mathrm{C}_{4} \mathrm{H}_{10}+\Delta \rightarrow \mathrm{C}_{4} \mathrm{H}_{9}+\mathrm{H} \\
\mathrm{C}_{4} \mathrm{H}_{9} \rightarrow \mathrm{CH}_{3}+\mathrm{C}_{3} \mathrm{H}_{6} \\
\mathrm{C}_{4} \mathrm{H}_{9} \rightarrow \mathrm{C}_{2} \mathrm{H}_{5}+\mathrm{C}_{2} \mathrm{H}_{4} \\
\mathrm{CH}_{3}+\mathrm{C}_{4} \mathrm{H}_{10} \rightarrow \mathrm{CH}_{4}+\mathrm{C}_{4} \mathrm{H}_{9} \\
\mathrm{C}_{2} \mathrm{H}_{5}+\mathrm{C}_{4} \mathrm{H}_{10} \rightarrow \mathrm{C}_{2} \mathrm{H}_{6}+\mathrm{C}_{4} \mathrm{H}_{9}
\end{gathered}
$$

$\mathrm{CH}_{3}, \mathrm{C}_{2} \mathrm{H}_{5}$ and $\mathrm{C}_{4} \mathrm{H}_{9}$ free radicals are the intermediates of the reactions. But, the above stable products can be formed directly via the primary decomposition reactions of $n$-butane too, not involving the secondary reactions.

$$
\begin{aligned}
& \mathrm{C}_{4} \mathrm{H}_{10}+\Delta \rightarrow \mathrm{CH}_{4}+\mathrm{C}_{3} \mathrm{H}_{6} \\
& \mathrm{C}_{4} \mathrm{H}_{10}+\Delta \rightarrow \mathrm{C}_{2} \mathrm{H}_{6}+\mathrm{C}_{2} \mathrm{H}_{4}
\end{aligned}
$$

In addition, the primary decomposition reactions of $n$ butane can also produce $\mathrm{CH}_{3}, \mathrm{C}_{2} \mathrm{H}_{5}$ and $\mathrm{C}_{3} \mathrm{H}_{7}$ radical products. 


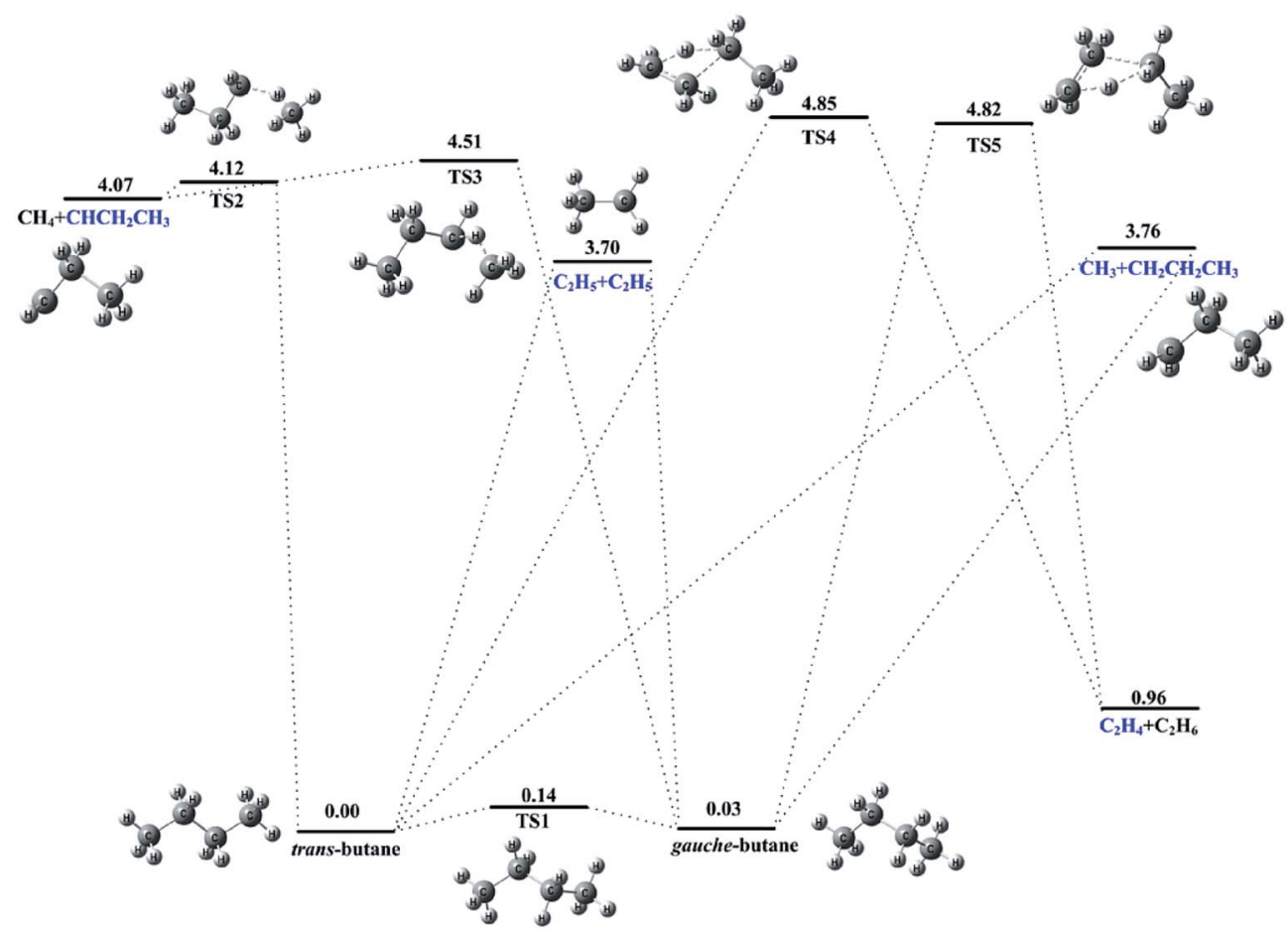

Fig. 5 Potential energy surface and relative energy of the primary products involved in the pyrolysis of $n$-butane calculated at the level of $\operatorname{CCSD}(T) /$ aug-cc-pVTZ//B3LYP/6-311+G(d,p) and given in eV. Optimized geometries of the reactant, transition states (TS) and products are also presented therein.

$$
\begin{gathered}
\mathrm{C}_{4} \mathrm{H}_{10}+\Delta \rightarrow \mathrm{CH}_{3}+\mathrm{C}_{3} \mathrm{H}_{7} \\
\mathrm{C}_{4} \mathrm{H}_{10}+\Delta \rightarrow \mathrm{C}_{2} \mathrm{H}_{5}+\mathrm{C}_{2} \mathrm{H}_{5}
\end{gathered}
$$

The successful identification of the reaction intermediates in experiment, especially the reactive radicals, is the key to reveal and demonstrate its decomposition mechanisms. The thermal decomposition of $n$-butane via the reactions (8) and (9) had been approved in shock tube by Hanson et al. ${ }^{4}$ In previous flow reactor experiment $\mathrm{CH}_{3}$ and $\mathrm{C}_{2} \mathrm{H}_{5}$ radical products, with no $\mathrm{C}_{3} \mathrm{H}_{7}$ and $\mathrm{C}_{4} \mathrm{H}_{9}$ radicals, were also detected by synchrotron VUV PIMS. $^{19}$

As shown in Fig. 2 and 3, in the present flash pyrolysis study of $n$-butane the products including the stable species of $\mathrm{C}_{2} \mathrm{H}_{4}$ and $\mathrm{C}_{3} \mathrm{H}_{6}$ and the radicals of $\mathrm{CH}_{3}, \mathrm{C}_{2} \mathrm{H}_{5}$ and $\mathrm{C}_{3} \mathrm{H}_{7}$ have been observed in the TPEPICO TOF mass spectra. $\mathrm{C}_{3} \mathrm{H}_{7}$ radical products are directly and successfully identified in the mass spectra for the first time. No $\mathrm{C}_{4} \mathrm{H}_{9}$ radical products, whose ionization energy is located at $8.02 \mathrm{eV},{ }^{31}$ was observed in our experiments. Due to the high temperature and the short contact time in the SiC tube, the thermal decomposition of $n$-butane can be taken place with high efficiency. So we believe that all the products observed in our experiments were mainly formed from the reactions of (6)-(9).

To elucidate the present experimental results, the decomposition of $n$-butane was also investigated by using quantum chemical calculations. The method of Becke three-parameter exchange functional with the Lee, Yang, and Parr correlation functional (B3LYP) with the $6-311+G(d, p)$ basis set was employed for molecular geometry optimizations and harmonic vibrational frequency analysis. ${ }^{45}$ The intrinsic reaction coordinate (IRC) calculations were also carried out to probe transition states between the reactants and products and to characterize the reaction profiles and elucidate the decomposition channels. ${ }^{46,47}$ Then the high-level method of coupled cluster method with single, double, and non-iterative triple excitations $(\operatorname{CCSD}(\mathrm{T}))^{48}$ with the aug-cc-pVTZ basis set was adopted to refine electronic energies based on the optimized B3LYP/6-311+G(d,p) structures. The corrections of zero point vibrational energies (ZPE) had been taken into account with the method of B3LYP/6$311+\mathrm{G}(\mathrm{d}, \mathrm{p})$. All the calculations were performed with the Gaussian 09 program. ${ }^{49}$

The potential energy surface together with the optimized molecular structures and their relative energies to the ground state of $n$-butane is presented in Fig. 5 . It is shown that $n$-butane has two conformers with trans and gauche structures. The energy of the trans conformer is a litter smaller than that of the gauche and has a more stable configuration. The isomerization between the trans and gauche conformers can be proceeded via a transition state (TS1) with a small height barrier of $0.14 \mathrm{eV}$. The barrier is so small that the products in the high temperature pyrolysis can be formed from the both conformers.

The pyrolysis pathways observed in the present experiments were calculated and then the decomposition mechanisms of $n$ butane can be inferred. As shown in Fig. 5, $\mathrm{CH}_{3}$ and its accompanying $\mathrm{C}_{3} \mathrm{H}_{7}$ radical products corresponding to the reaction (8) were produced from the direct fission of the C1-C2 bond of $n$ butane and no barrier was found on the decomposition route. 
The C1-C2 bond energy of $n$-butane is calculated to be $3.76 \mathrm{eV}$. Similarly, two $\mathrm{C}_{2} \mathrm{H}_{5}$ radical products were formed directly through the $\mathrm{C} 2-\mathrm{C} 3$ bond fission of $n$-butane and the bond energy is $3.70 \mathrm{eV}$. But, the dissociation mechanisms to produce the $\mathrm{C}_{2} \mathrm{H}_{4}$ or $\mathrm{C}_{3} \mathrm{H}_{6}$ products observed in experiments are a litter complicated than those of the $\mathrm{CH}_{3}$ and $\mathrm{C}_{2} \mathrm{H}_{5}$ products. The calculations show that the process of $\mathrm{H}$ atom migration should be involved in the decomposition of $n$-butane to produce $\mathrm{CH}_{4}$ and $\mathrm{C}_{3} \mathrm{H}_{6}$ species. As shown in Fig. 5, this speculation is attested and the two transition states (TS2 and TS3) with a complex structure of $\mathrm{CH}_{4}^{-}$ $\mathrm{CHCH}_{2} \mathrm{CH}_{3}$ were also identified along the decomposition routes. For the productions of $\mathrm{C}_{2} \mathrm{H}_{4}$ and $\mathrm{C}_{2} \mathrm{H}_{6}$ species, two four-memberring transition states of TS4 and TS5 are determined along the routes. The energy barriers for this production channel from the trans and gauche conformers of $n$-butane are calculated at 4.85 and $4.82 \mathrm{eV}$, respectively.

\section{Conclusion}

A molecular beam flash pyrolysis micro-reactor coupled with a threshold photoelectron photoion coincidence spectrometer has been constructed at Hefei synchrotron and utilized to investigate thermal decomposition of hydrocarbons. The high temperature and the short contact time in the micro-reactor allow for the thermal decomposition with high efficiency. The pyrolysis of $n$-butane has been selected as a representative example and analyzed. The primary pyrolysis products including $\mathrm{CH}_{3}, \mathrm{C}_{2} \mathrm{H}_{5}$ and $\mathrm{C}_{3} \mathrm{H}_{7}$ free radicals were detected and determined with TPEPICO TOF mass spectra and mass-selected TPES. Vibrational structures in the TPES of $\mathrm{CH}_{3}, \mathrm{C}_{2} \mathrm{H}_{5}$ and $\mathrm{C}_{3} \mathrm{H}_{6}$ products were identified and assigned and their ionization energies were measured, which compared satisfactorily to the existing literature data. The fine structures of the mass-selected TPES offer great selectivity and sensitivity in comparable to the traditional PIE spectra.

The potential energy surface related to the thermal decomposition of $n$-butane has been calculated with the high-level theoretical method of $\operatorname{CCSD}(\mathrm{T}) /$ aug-cc-pVTZ//B3LYP/6$311+\mathrm{G}(\mathrm{d}, \mathrm{p})+\mathrm{ZPE}$ and the detailed dissociation mechanisms have been discussed and revealed. All the products observed in our experiments were mainly formed from the primary decomposition reactions of $n$-butane. The trans and gauche conformers of $n$-butane should be involved in the pyrolysis. The productions of the $\mathrm{CH}_{3}$ radical and its accompanying $\mathrm{C}_{3} \mathrm{H}_{7}$ products, and two $\mathrm{C}_{2} \mathrm{H}_{5}$ radical products, are simple and just through the direct bond fission of $n$-butane. But, the dissociation mechanisms to produce $\mathrm{C}_{3} \mathrm{H}_{6}$ or $\mathrm{C}_{2} \mathrm{H}_{4}$ fragments are a litter more complicated than those of the $\mathrm{CH}_{3}$ and $\mathrm{C}_{2} \mathrm{H}_{5}$ products. Transition states with four-member-ring structures were determined in the production of $\mathrm{C}_{2} \mathrm{H}_{4}$ and $\mathrm{C}_{2} \mathrm{H}_{6}$. In addition, to explain the pyrolysis to the $\mathrm{CH}_{4}$ and $\mathrm{C}_{3} \mathrm{H}_{6}$ products, a mechanism of $\mathrm{H}$ atom migration should be taken into account.

\section{Acknowledgements}

This work was supported by the National Natural Science Foundation of China (91644109, 91544105), the National Key
Research and Development Program of China (2016YFC0200300, 2016YFC0202205), National Key Scientific Instruments and Equipment Development Program of China (2012YQ220113) and the Natural Science Foundation of Anhui Province (1608085MB35). The authors are grateful to Dr Xiaoguo Zhou for helpful discussion in preparation of the manuscript.

\section{References}

1 B. S. Haynes and H. G. Wagner, Soot formation, Prog. Energy Combust. Sci., 1981, 7(4), 229-273.

2 K. Kohse-Hoinghaus, P. Osswald, T. A. Cool, T. Kasper, N. Hansen, F. Qi, C. K. Westbrook and P. R. Westmoreland, Biofuel combustion chemistry: from ethanol to biodiesel, Angew. Chem., Int. Ed., 2010, 49(21), 3572-3597.

3 F. Qi, Combustion chemistry probed by synchrotron VUV photoionization mass spectrometry, Proc. Combust. Inst., 2013, 34, 33-63.

4 M. A. Oehlschlaeger, D. F. Davidson and R. K. Hanson, Hightemperature thermal decomposition of isobutane and $n$ butane behind shock waves, J. Phys. Chem. A, 2004, 108(19), 4247-4253.

5 A. V. Friderichsen, J. G. Radziszewski, M. R. Nimlos, P. R. Winter, D. C. Dayton, D. E. David and G. B. Ellison, The infrared spectrum of the matrix-isolated phenyl radical, J. Am. Chem. Soc., 2001, 123(9), 1977-1988.

$6 \mathrm{~J}$. H. Purnell and C. P. Quinn, Nature of the reactions involved in the pyrolysis of $n$-butane inhibited by propylene, Nature, 1961, 189(4765), 656-658.

7 E. Goos, H. Hippler, K. Hoyermann and B. Jurges, Laser powered homogeneous pyrolysis of butane initiated by methyl radicals in a quasi-wall-free reactor at 750-1000 K, Phys. Chem. Chem. Phys., 2000, 2(22), 5127-5132.

8 B. Shukla, A. Susa, A. Miyoshi and M. Koshi, In situ direct sampling mass spectrometric study on formation of polycyclic aromatic hydrocarbons in toluene pyrolysis, $J$. Phys. Chem. A, 2007, 111(34), 8308-8324.

9 T. Baer, in Gas phase ion chemistry, ed. M. T. Bowers, Academic, New York, 1979, ch. 5, vol. 1, pp. 153-196.

10 X. F. Tang, X. G. Zhou, M. L. Niu, S. L. Liu, J. D. Sun, X. B. Shan, F. Y. Liu and L. S. Sheng, A threshold photoelectron-photoion coincidence spectrometer with double velocity imaging using synchrotron radiation, Rev. Sci. Instrum., 2009, 80(11), 113101.

11 A. Bodi, P. Hemberger, T. Gerber and B. Sztaray, A new double imaging velocity focusing coincidence experiment: $\mathrm{i}^{2}$ PEPICO, Rev. Sci. Instrum., 2012, 83(8), 083105.

12 G. A. Garcia, B. K. C. de Miranda, M. Tia, S. Daly and L. Nahon, DELICIOUS III: a multipurpose double imaging particle coincidence spectrometer for gas phase vacuum ultraviolet photodynamics studies, Rev. Sci. Instrum., 2013, 84, 053112.

13 A. Bodi, P. Hemberger, D. L. Osborn and B. Sztaray, Massresolved isomer-selective chemical analysis with imaging photoelectron photoion coincidence spectroscopy, J. Phys. Chem. Lett., 2013, 4(17), 2948-2952. 
14 J. Kruger, G. A. Garcia, D. Felsmann, K. Moshammer, A. Lackner, A. Brockhinke, L. Nahon and K. KohseHoinghaus, Photoelectron-photoion coincidence spectroscopy for multiplexed detection of intermediate species in a flame, Phys. Chem. Chem. Phys., 2014, 16(41), 22791-22804.

15 G. A. Garcia, X. F. Tang, J. F. Gil, L. Nahon, M. Ward, S. Batut, C. Fittschen, C. A. Taatjes, D. L. Osborn and J. C. Loison, Synchrotron-based double imaging photoelectron/photoion coincidence spectroscopy of radicals produced in a flow tube: $\mathrm{OH}$ and OD, J. Chem. Phys., 2015, 142(16), 164201.

16 M. A. Oehlschlaeger, D. F. Davidson, J. T. Herbon and R. K. Hanson, Shock tube measurements of branched alkane ignition times and $\mathrm{OH}$ concentration time histories, Int. J. Chem. Kinet., 2004, 36(2), 67-78.

17 S. L. K. Wittig, Study of the thermal decomposition of $n$ butane, Phys. Fluids, 1969, 12(5), I133-I135.

18 D. M. Golden, Z. B. Alfassi and P. C. Beadle, Very lowpressure pyrolysis (VLPP) of alkanes: n-butane, 2,3dimethylbutane, 2,2',3,3'-tetramethylbutane, and isobutane, Int. J. Chem. Kinet., 1974, 6(3), 359-370.

19 Y.-J. Zhang, W.-H. Yuan, J.-H. Cai, L.-D. Zhang, F. Qi and Y.-Y. Li, Product identification and mass spectrometric analysis of $n$-butane and i-butane pyrolysis at low pressure, Chin. J. Chem. Phys., 2013, 26(2), 151-156.

20 M. S. Brogan, J. A. Cairns and T. J. Dines, Raman spectroscopic study of the thermal and catalytic decomposition of butane, J. Raman Spectrosc., 1994, 25(12), 927-932.

21 C.-H. Chin and S.-H. Lee, Comparison of two-body and threebody decomposition of ethanedial, propanal, propenal, $n$ butane, 1-butene, and 1,3-butadiene, J. Chem. Phys., 2012, 136(2), 024308.

22 B. K. C. de Miranda, C. Alcaraz, M. Elhanine, B. Noller, P. Hemberger, I. Fischer, G. A. Garcia, H. Soldi-Lose, B. Gans, L. A. V. Mendes, S. Boye-Peronne, S. Douin, J. Zabka and P. Botschwina, Threshold photoelectron spectroscopy of the methyl radical isotopomers, $\mathrm{CH}_{3}, \mathrm{CH}_{2} \mathrm{D}$, $\mathrm{CHD}_{2}$ and $\mathrm{CD}_{3}$ : synergy between VUV synchrotron radiation experiments and explicitly correlated coupled cluster calculations, J. Phys. Chem. A, 2010, 114(14), 4818-4830.

23 P. Hemberger, M. Steinbauer, M. Schneider, I. Fischer, M. Johnson, A. Bodi and T. Gerber, Photoionization of three isomers of the $\mathrm{C}_{9} \mathrm{H}_{7}$ radical, J. Phys. Chem. A, 2010, 114(14), 4698-4703.

24 F. Zhang, R. I. Kaiser, V. V. Kislov, A. M. Mebel, A. Golan and M. Ahmed, A VUV photoionization study of the formation of the indene molecule and its isomers, J. Phys. Chem. Lett., 2011, 2(14), 1731-1735.

25 Y. Zhu, X. Wu, X. F. Tang, Z. Wen, F. Liu, X. Zhou and W. Zhang, Synchrotron threshold photoelectron photoion coincidence spectroscopy of radicals produced in a pyrolysis source: the methyl radical, Chem. Phys. Lett., 2016, 664, 237-241.

26 D. W. Kohn, H. Clauberg and P. Chen, Flash pyrolysis nozzle for generation of radicals in a supersonic jet expansion, Rev. Sci. Instrum., 1992, 63(8), 4003-4005.
27 J. A. Blush, H. Clauberg, D. W. Kohn, D. W. Minsek, Z. Xu and P. Chen, Photoionization mass and photoelectron spectroscopy of radicals, carbenes, and biradicals, Acc. Chem. Res., 1992, 25(9), 385-392.

28 Q. Guan, K. N. Urness, T. K. Ormond, D. E. David, G. B. Ellison and J. W. Daily, The properties of a microreactor for the study of the unimolecular decomposition of large molecules, Int. Rev. Phys. Chem., 2014, 33(4), 447-487.

29 A. T. J. B. Eppink and D. H. Parker, Velocity map imaging of ions and electrons using electrostatic lenses: application in photoelectron and photofragment ion imaging of molecular oxygen, Rev. Sci. Instrum., 1997, 68(9), 3477-3484.

30 B. Sztaray and T. Baer, Suppression of hot electrons in threshold photoelectron photoion coincidence spectroscopy using velocity focusing optics, Rev. Sci. Instrum., 2003, 74(8), 3763-3768.

31 NIST Chemistry WebBook, http://webbook.nist.gov/ chemistry/, accessed December, 2016.

32 W. A. Chupka and J. Berkowit, Photoionization of ethane, propane, and $n$-butane with mass analysis, J. Chem. Phys., 1967, 47(8), 2921-2933.

33 J. Dyke, A. Ellis, N. Jonathan and A. Morris, Vacuum ultraviolet photoelectron spectroscopy of transient species. Part 18. The cyclopropyl, isopropyl and $n$-propyl radicals, $J$. Chem. Soc., Faraday Trans. 2, 1985, 81, 1573-1586.

$34 \mathrm{~K}$. Vasilatou and F. Merkt, Torsional vibrational structure of the propene radical cation studied by high-resolution photoelectron spectroscopy, J. Chem. Phys., 2011, 135(12), 124310.

35 R. A. Mackie, A. M. Sands, S. W. J. Scully, D. M. P. Holland, D. A. Shaw, K. F. Dunn and C. J. Latimer, The molecular and dissociative photoionization of ethane in the inner and outer valence energy regions, J. Phys. B: At., Mol. Opt. Phys., 2002, 35(4), 1061-1069.

36 B. Ruscic, J. Berkowitz, L. A. Curtiss and J. A. Pople, The ethyl radical - Photoionization and theoretical studies, J. Chem. Phys., 1989, 91(1), 114-121.

37 G. R. Branton, D. C. Frost, T. Makita, C. A. McDowell and I. A. Stenhouse, Photoelectron spectra of some polyatomic molecules, Philos. Trans. R. Soc., A, 1970, 268(1184), 77-85.

38 R. Signorell and F. Merkt, The first rotationally resolved spectrum of $\mathrm{CH}_{4}^{+}$, J. Chem. Phys., 1999, 110(5), 2309-2311.

39 A. M. Schulenburg, C. Alcaraz, G. Grassi and F. Merkt, Rovibrational photoionization dynamics of methyl and its isotopomers studied by high-resolution photoionization and photoelectron spectroscopy, J. Chem. Phys., 2006, 125(10), 104310.

40 J. A. Blush, P. Chen, R. T. Wiedmann and M. G. White, Rotationally resolved threshold photoelectron spectrum of the methyl radical, J. Chem. Phys., 1993, 98(4), 3557-3559.

41 A. Katrib and J. W. Rabalais, Electronic interaction between the vinyl group and its substituents, J. Phys. Chem., 1973, 77(19), 2358-2363.

42 B. Gans, G. A. Garcia, S. Boye-Peronne, J.-C. Loison, S. Douin, F. Gaie-Levrel and D. Gauyacq, Absolute photoionization cross section of the ethyl radical in the range $8-\mathbf{1 1 . 5} \mathrm{eV}$ : 
synchrotron and vacuum ultraviolet laser measurements, $J$. Phys. Chem. A, 2011, 115(21), 5387-5396.

43 X. F. Tang, G. A. Garcia and L. Nahon, Adiabatic ionization energies of the overlapped $\mathrm{A}^{2} \mathrm{~A}_{1}$ and $\mathrm{B}^{2} \mathrm{E}$ electronic states in $\mathrm{CH}_{3} \mathrm{Cl}^{+} / \mathrm{CH}_{3} \mathrm{~F}^{+}$measured with double imaging electron/ ion coincidence, Phys. Chem. Chem. Phys., 2015, 17(26), 16858-16863.

44 S. H. Yoon, N.-K. Park, T. J. Lee, K. J. Yoon and G. Y. Han, Hydrogen production by thermocatalytic decomposition of butane over a carbon black catalyst, Catal. Today, 2009, 146(1-2), 202-208.

45 A. D. Becke, Density functional thermochemistry. 3. The role of exact exchange, J. Chem. Phys., 1993, 98(7), 5648-5652.

46 C. Gonzalez and H. B. Schlegel, An improved algorithm for reaction path following, J. Chem. Phys., 1989, 90(4), 21542161.

47 C. Gonzalez and H. B. Schlegel, Reaction path following in mass-weighted internal coordinates, J. Phys. Chem., 1990, 94(14), 5523-5527.

48 J. A. Pople, M. Headgordon and K. Raghavachari, Quadratic configuration interaction. A general technique for determining electron correlation energies, J. Chem. Phys., 1987, 87(10), 5968-5975.

49 M. J. Frisch, G. W. Trucks, H. B. Schlegel, G. E. Scuseria, M. A. Robb, J. R. Cheeseman, G. Scalmani, V. Barone, B. Mennucci, G. A. Petersson, H. Nakatsuji, M. Caricato, X. Li, H. P. Hratchian, A. F. Izmaylov, J. Bloino, G. Zheng, J. L. Sonnenberg, M. Hada, M. Ehara and R. F. K. Toyota, J. Hasegawa, M. Ishida, T. Nakajima, Y. Honda, O. Kitao, H. Nakai, T. Vreven, J. A. Montgomery Jr, J. E. Peralta, F. Ogliaro, M. Bearpark, J. J. Heyd, E. Brothers, K. N. Kudin, V. N. Staroverov, R. Kobayashi, J. Normand, K. Raghavachari, A. Rendell, J. C. Burant, S. S. Iyengar, J. Tomasi, M. Cossi, N. Rega, J. M. Millam, M. Klene, J. E. Knox, J. B. Cross, V. Bakken, C. Adamo, J. Jaramillo, R. Gomperts, R. E. Stratmann, O. Yazyev, A. J. Austin, R. Cammi, C. Pomelli, J. W. Ochterski, R. L. Martin, K. Morokuma, V. G. Zakrzewski, G. A. Voth, P. Salvador, J. J. Dannenberg, S. Dapprich, A. D. Daniels, Ö. Farkas, J. B. Foresman, J. V. Ortiz, J. Cioslowski and D. J. Fox, Gaussian 09, Gaussian, Inc., Wallingford CT, 2009. 